\title{
Mula Bandha and Raising Awareness about Pelvic Floor Dysfunction
}

\author{
Marceil May ${ }^{1}$ and Cynthia E Neville ${ }^{2 *}$ PT, DPT, WCS \\ ${ }^{1}$ Owner of Anam Cara Studios specializing in Healing \& Creative Arts Therapy, USA \\ ${ }^{2}$ National Director, Pelvic Health \& Wellness, FYZICAL Therapy \& Balance Centers, USA
}

Submission: February 20, 2018; Published: April 19, 2018

*Corresponding author: Cynthia E Neville, PT, DPT, WCS, National Director, Pelvic Health \& Wellness, FYZICAL Therapy \& Balance Centers, 25241 Elementary Way, Suite 200, Bonita Springs, FL 34135, USA, Tel: 239-810-9331; Email: cneville@fyzicalswfl.com

Abstract

Pelvic floor disorders (PFDs) such as urinary incontinence are common amongst both clients and yoga and fitness instructors. Yet, awareness of pelvic floor function and dysfunction, and the language and dialogue to address these potentially devastating disorders is lacking. This article proposes to increase awareness about the function and dysfunction of the pelvic floor in yoga and fitness education, training, and practice.

Keywords: Pelvic floor; Pelvic floor dysfunction; Urinary incontinence; Mula bandha

Abbreviations: PFD: Pelvic Floor Dysfunction; PFM: Pelvic Floor Muscles; POP: Pelvic Organ prolapse; UI: Urinary Incontinence; PA: Physical Activity

\section{Introduction}

Imagine you are a fitness and yoga/Pilates instructor with a college degree in exercise physiology and over 20 years of experience including a vast array of professional training as well as continuing education units. Throughout your career, you have worked with hundreds of men and women ranging from 16 to 85 years of age. Around the age of 45, you begin to experience occasional leaking of urine (urinary incontinence or UI) while teaching yoga classes. You are a "practice what you preach" kind of person, so you exercise regularly with the most effective, welltested modalities of yoga, Pilates, cardiovascular and strength exercises. Now, because you are leaking, you focus on mula bandha in your yoga practice, and you begin to perform "Kegel" exercises regularly. In spite of performing what you believe are corrective exercises for your issue, you begin to have constant pain and pressure in the region of your anus. You decide it is time to consult your health care provider, who recommends a colonoscopy, despite your young age and low risk profile. After the diagnostic procedure, the results come back completely normal. Both you and your physician are perplexed. In the meantime, your symptoms of urinary urgency and frequency increase, as well as pain and pressure in the anus and perineum.

\section{Scope of the Problem}

Urinary incontinence (UI), urinary frequency and urgency, nocturia (waking at night to urinate), pain and pressure in the perineum and/or anal region, painful vaginal penetration, difficulty evacuating the bowels, and loss of stool are all signs of pelvic floor dysfunction (PFD). Female PFD can manifest not only as urinary and/or fecal incontinence, but also as pelvic organ prolapse of the female reproductive organs (POP), or a variety of pelvic pain symptoms. Thirty to $50 \%$ of all women suffer from some form of PFD [1]. Fitness and yoga instructors are not exempt. Bo [2] reported that UI is prevalent in fitness instructors, particularly female instructors. In her survey of 1473 fitness instructors, more than $20 \%$ reported experiencing UI during various forms of physical activity. Yoga and Pilates instructors reported the highest rates of UI at $25 \%$. The population at large, along with fitness instructors, harbor many misconceptions and prejudices about pelvic floor dysfunction-mainly about urinary incontinence-that stand in the way of appropriate care and effective prevention [1]. Fitness instructors may believe that a little leakage of urine is to be expected because of the physical demands placed on the body during exercise. Many people believe that incontinence is a normal part of aging. Yet, the unintentional leakage of urine is never normal.

One evening you mention your concern about your symptoms to your friend who happens to be a Doctor of Physical Therapy specializing in pelvic health. Physical therapist education and training now leads to a Doctorate degree (Doctor of Physical Therapy or DPT), and many DPTs are specializing in specific areas of clinical practice. Your friend is board certified in Women's Health (Women's Health Certified Specialist or WCS). She has undergone 
extensive postgraduate training to diagnose and treat pelvic floor disorders. She explains that your symptoms are characteristic of PFD. She encourages you to schedule a pelvic physical therapy evaluation.

Several layers of evaluation and diagnosis exist for PFDs. A general medical practitioner, gynecologist, urologist, or urogynecologist typically performs the medical evaluation and diagnosis [3]. Evaluation for PFD includes vaginal and anal/ rectal digital examination, examination for POP, assessment for local hormone deficiency, evaluation of bladder function, testing for infection and other pathology, and assessment for contractility of pelvic floor. Other medical tests might include, perineal ultrasonography for bladder neck mobility and POP, clinical stress test; urine loss upon coughing while standing, the urinary pad test, urodynamic testing, and cystoscopy.

Many aspects of PFD are related to musculoskeletal dysfunction, so it is common for women with PFD to undergo medical testing and find out that the results are "normal". Physical therapist examination for PFD focuses on the musculoskeletal function of the pelvic floor muscles and associated lumbar spine, pelvic girdle, and hip anatomy. The pelvic floor examination is performed vaginally and/or via the anus and rectum, and is designed to assess all aspects of the functioning of the pelvic floor muscles. Specifically, how do the pelvic floor muscles (PFM) contract and relax, what power is generated by the PFM during contraction, what is the coordination of the PFM contraction and relaxation with the abdominal and other muscles, is the timing of the PFM contraction effective, can the PFM sustain repeated sustained contractions demonstrating appropriate endurance, and is there any pain in the PFM and the pelvic floor in general.

At your physical therapy appointment, you are diagnosed with PFD. Your Doctor identifies a hyper-flexed coccyx (tailbone), which is shortening and altering the muscle function of the pelvic floor, causing pain and bladder symptoms. You begin attending physical therapy and you learn that by previously performing intensive "Kegel" exercises, you may have actually worsened your symptoms. Over the next 6 weeks of physical therapy treatment, you are able to improve pelvic floor muscle function, and eliminate UI and pain.

Many people, including medical doctors as well as yoga and fitness instructors, are not aware that physical therapy is a first line of treatment for PFDs, or that this specialized form of treatment is even available. Physical therapy treatment of pelvic floor disorders focuses on restoration of pelvic floor muscle function. Pelvic physical therapy interventions are multimodal including a variety of treatments. Re-education of pelvic floor muscle contraction and relaxation is critical. Pelvic floor muscles must be able to both contract and relax. One of the reasons that "Kegel" exercises are often ineffective is because these core muscles may be overactive, weak, and poorly relaxing, Overactive pelvic floor muscles are often the culprit of symptoms of urinary urgency and pelvic pain conditions. Pelvic physical therapists may apply neuromuscular electrical stimulation and SEMG perineal biofeedback initially for "down-training" overactive or poorly functioning pelvic floor muscles, to restore the ability of these muscles to relax, prior to training them for strength and endurance. Manual physical therapy techniques are also a key component of treatment, and include internal vaginal or rectal myofascial release and massage, connective tissue manipulation, mobilization of scar tissue, especially at the perineum from episiotomy or childbirth injuries. Treatment of joint restrictions in the lumbar spine, pelvic girdle (sacroiliac joints, pubic symphysis, and sacro-coccygeal joints) and hips is integrated into the plan of care.

The prevalence of PFDs in women and men in the US and around the world is staggering. Yet, in the extensive training one undergoes as a fitness or yoga instructor, information about PFD is lacking. PFD not only causes symptoms, but is also an indication of a poorly functioning core. When movement professionals are not aware of the signs of PFD, they may miss the opportunity to provide a critical component of health awareness to their students/clients. They may also find that they cannot achieve the results of exercise and training that they would otherwise expect with their clients. Within the context of 200/500 hour yoga training programs, the consensus is that there is very little shared about the understanding with the pelvic floor muscles. Mula bandha is the main concept surrounding activation of the pelvic floor in yoga. According to YogaInternational.com Mula bandha, in which muscles are tightly contracted at the center of the perineum, is an energetic practice that accompanies both pranayama (focused breathing techniques) and meditation. However, this "tightly contracting of the perineum" is only one aspect of pelvic floor muscle function.

There is a great need and opportunity for teachers of yoga to learn about the practical and functional aspects of the pelvic floor muscles. By using clear and specific language about the PFM and by incorporating techniques to achieve both contraction and relaxation, instructors can enable their clients to better access mula bandha, and to improve pelvic floor muscle function. Instructors should strive for the ability to incorporate accurate verbal cues of PFM contraction and relaxation in yoga postures and fitness exercise routines. This begs the question; how do we open up the dialogue and create an awareness of this crucial aspect of practice?

A large influx of new yoga, Pilates, and fitness students and teachers is occurring in the US (ideafit.com). Intentional and structured education addressing function of the pelvic floor within the context of yoga/Pilates/fitness instructors teaching and training is crucial. Yet, in our search for resources, including the websites of the International Association of Yoga Therapists and the Yoga Alliance, we found that out of 50 studies quoted, not one speaks to pelvic health and wellness. An expert review in the American Journal of Obstetrics \& Gynecology was conducted to summarize studies reporting the association between physical activity (PA) and PFDs [4]. The authors propose that PA 


\section{Journal of Yoga and Physiotherapy}

is a potentially modifiable risk factor" for PFDs, and identifying those at risk is crucial. They report that UI during exercise is common and is more prevalent in women during high-impact sports. Twenty eight percent of those who report UI find it to be a barrier to exercise. Mild to moderate physical activity, such as brisk walking, decreases both the odds of having and the risk of developing UI. In older women, mild to moderate activity also decreases the odds of having fecal incontinence. Most physical exercise offers many additional health benefits while not doing harm to the pelvic floor.

\section{Conclusion}

The relationship between exercise, particularly strenuous activity, and PFDs is clear. So how can we best serve our clients? The responsibility of an instructor is to first, circumvent exercise induced PFD, and second, help to identify PFD when it occurs, so that appropriate treatment is offered. Can we create awareness and disseminate skills and knowledge of the function and dysfunction of the pelvic floor into the educational programs of yoga, wellness and fitness professionals? Perhaps, initially, it might be as simple as using the concept of the energy center of mula bandha as an entry point of awareness for clients/students. Increasing awareness of this powerful and critical center of the body can open the dialogue about the function and dysfunction of the pelvic floor, and can lead to specific instruction during a class or appointment. Instructors should be able to provide accurate verbal instructions in pelvic floor muscle contraction and relaxation. Fitness/ yoga/ Pilates instructors can help identify clients with PFD with simple questions, such as do you leak urine, even a small amount?" or by using questionnaires [3]. When a client is identified as possibly having a PFD, action steps include referral to a medical professional or a pelvic floor physical therapist. Increasing awareness to address PFD offers a wonderful and valuable bridge between "living with" pelvic floor dysfunction and enjoying a life free from pain, embarrassment and helplessness.

\section{How to Find a Pelvic Physical Therapist}

Instructors, physicians, and clients can seek out local Pelvic Health PTs for referral for evaluation and treatment of PFD through the American Physical Therapy Association's website, www.APTA.org, using the "Find a PT" feature, and searching under the specialty of "Women's Health".

\section{Examples of appropriate verbal cues for pelvic floor muscle contraction}

1. Start with inhale, then during exhale squeeze and close the anus, vagina, and urethra, and feel the muscles around them lift upward and inward towards your navel and head. Hold, then release.

2. Imagine these muscles are an elevator. Squeeze the openings to "close the doors", then lift the muscles up and the elevator moves towards the penthouse.
3. Feel the bones that you are sitting on (ischial tuberosities). Try to move them towards each other using the muscles inside the pelvis. Find the pubic bone in front, and the tailbone in back. Try to move the pubic bone and the tailbone towards each other. Try to the draw the bones together for 5-10 seconds. Then release

\section{Examples of appropriate verbal cues for pelvic floor muscle relaxation}

1. Allow the sit bones and the pubic and tailbone to move apart in relaxation. Gently try to push them apart for a greater release.

2. After moving the elevator up to the penthouse, allow the elevator to drop back down to the ground floor. Allow the "doors" of the anus and vagina to open. Try to allow this relaxation to extend further to the "basement" by gently bulging the lower abdomen as you let your breath escape.

\section{Conflicts of Interest}

We declare no conflicts of interest in this work.

\section{Short Biographies}

Dr. Cynthia Neville is a certified Women's Health Specialist (WCS) and expert in pelvic health rehabilitation committed to creating successful programs for delivering pelvic health rehabilitation services to women and men across the country. She is the National Director of Pelvic Health \& Wellness for FYZICAL Therapy \& Balance Centers. FYZICAL is changing health care by making pelvic health rehabilitation available to everyone across the country.

Marceil May is a Registered Kripalu Yoga Instructor, 500RYT, BS Exercise Science, PH Pilates Cert, Cert. Neuromuscular Therapist and having over 25 years of experience supporting individuals in their self-care practices of movement, breathing and connection by integrating the modalities of her extensive training in the art \& science of the mind and body. Her personal mission is to encourage the cultivation of awareness, compassion \& connection to self and others to elevate joy \& vitality.

\section{References}

1. (2007) Harninkontinenz. Gesundheitsberichterstattung des Bundes. Robert-Koch-Institut Band 39.

2. Bø K, Bratland Sanda S, Sundgot Borgen J (2011) Urinary incontinence among group fitness instructors including yoga and pilates teachers. Neurourol Urodyn 30(3): 370-373.

3. Jundt $\mathrm{K}$, Peschers U, Kentenich $\mathrm{H}$ (2015) The Investigation and treatment of female pelvic floor dysfunction. Dtsch Arztebl Int 112(3334): 564-574.

4. Nygaard I, Shaw JM (2016) Physical Activity and the pelvic floor. Am J Obstet Gynaecol 214(2): 164-171. 
(C) This work is licensed under Creative Commons Attribution 4.0 License DOI: 10.19080/JYP.2018.04.555647
Your next submission with Juniper Publishers will reach you the below assets

- Quality Editorial service

- Swift Peer Review

- Reprints availability

- E-prints Service

- Manuscript Podcast for convenient understanding

- Global attainment for your research

- Manuscript accessibility in different formats ( Pdf, E-pub, Full Text, Audio)

- Unceasing customer service

Track the below URL for one-step submission https://juniperpublishers.com/online-submission.php 